\title{
Correction to: Do Insurance Mandates Affect Racial Disparities in Outcomes for Children with Autism?
}

\author{
Pratik Doshi $^{1} \cdot$ J. Mick Tilford ${ }^{2} \cdot$ Songthip Ounpraseuth ${ }^{3} \cdot$ Dennis Z. Kuo ${ }^{4}$. Nalin Payakachat ${ }^{5}$
}

Published online: 7 February 2019

○) Springer Science+Business Media, LLC, part of Springer Nature 2019

\section{Correction to: \\ Maternal and Child Health Journal (2017) 21(2):351-366 https://doi.org/10.1007/s10995-016-2120-z}

The original version of this article unfortunately contained a mistake in the analysis of the Tables 4 and 5. All analyses were conducted based on information regarding insurance mandates for autism that were extracted in 2012 and then continued updating Table 5 (state mandates) up to 2016 when the manuscript got published. Therefore, information of insurance mandate got updated to reflect the most recent changes in autism mandate in several states. The main analysis (Table 4) has been rerun, including Wisconsin as a mandate state and excluding Connecticut, Kansas, and Kentucky. However, there is no change in the results. The Tables 4 and 5 are corrected with this correction.

The original article can be found online at https://doi.org/10.1007/ s10995-016-2120-z.

Nalin Payakachat npayakachat@uams.edu

1 University of Kentucky, Lexington, KY, USA

2 Department of Health Policy and Management, University of Arkansas for Medical Sciences, Little Rock, AR, USA

3 Department of Biostatistics, University of Arkansas for Medical Sciences, Little Rock, AR, USA

4 Department of Pediatrics, University of Arkansas for Medical Sciences, Little Rock, AR, USA

5 Department of Pharmacy Practice, University of Arkansas for Medical Sciences, 4301 W. Markham St, 522, Little Rock, AR, USA 
Table 4 Impact of private insurance mandates on racial disparities in outcomes of White and non-White children with ASDs across the 2005/06 and 2009/10 the National Survey of Children with Special Health Care Needs

\begin{tabular}{|c|c|c|c|c|c|c|}
\hline \multirow[t]{2}{*}{ Variable } & \multicolumn{3}{|l|}{ Unadjusted } & \multicolumn{3}{|l|}{ Adjusted } \\
\hline & Coefficients & $95 \% \mathrm{CI}$ & $p$ & Coefficients & $95 \% \mathrm{CI}$ & $p$ \\
\hline \multicolumn{7}{|l|}{ Care quality indicators } \\
\hline Had access to family-centered care & -0.409 & $-1.432,0.612$ & 0.432 & -0.453 & $-1.509,0.603$ & 0.400 \\
\hline Received coordinated, comprehensive and continuous care & -0.683 & $-1.915,0.548$ & 0.277 & -0.681 & $-1.927,0.564$ & 0.284 \\
\hline Any problems getting needed referrals & 1.028 & $-0.498,2.555$ & 0.187 & 1.281 & $-0.290,2.852$ & 0.110 \\
\hline Child unmet needs ratio & 0.133 & $-1.119,1.386$ & 0.835 & 0.111 & $-1.079,1.302$ & 0.854 \\
\hline \multicolumn{7}{|l|}{ Family economic outcomes } \\
\hline $\begin{array}{l}\text { Paid } \$ 501 \rightarrow \$ 1,000 \text { annual out-of-pocket expenses of the family } \\
\text { to take care of the affected child }\end{array}$ & -0.275 & $-1.335,0.784$ & 0.610 & -0.367 & $-1.549,0.814$ & 0.542 \\
\hline $\begin{array}{l}\text { CSHCN whose families experienced financial burden due to } \\
\text { child's condition }\end{array}$ & 0.069 & $-0.962,1.101$ & 0.895 & -0.011 & $-1.094,1.071$ & 0.983 \\
\hline $\begin{array}{l}\text { Spent } 5 \rightarrow 11 \text { h by families per week of CSHCN taking care of } \\
\text { their child }\end{array}$ & 0.552 & $-0.471,1.576$ & 0.290 & 0.748 & $-0.332,1.831$ & 0.175 \\
\hline $\begin{array}{l}\text { CSHCN whose families had to cut back on work hours or stop } \\
\text { working due to child's condition }\end{array}$ & -0.312 & $-1.314,0.689$ & 0.541 & -0.289 & $-1.321,0.741$ & 0.581 \\
\hline \multicolumn{7}{|l|}{ Child health outcomes } \\
\hline $\begin{array}{l}\text { Child's condition "Usually" or "Always" affects his/her ability to } \\
\text { do age-appropriate things }\end{array}$ & 0.533 & $-0.479,1.544$ & 0.302 & 0.636 & $-0.402,1.674$ & 0.229 \\
\hline $\begin{array}{l}\text { Child's condition affects "Some" or "A great deal" his/her ability } \\
\text { to do age-appropriate things }\end{array}$ & 0.316 & $-0.729,1.362$ & 0.553 & 0.327 & $-0.749,1.404$ & 0.551 \\
\hline
\end{tabular}

Models adjusted for age, race, poverty level of family, child unmet needs ratio, family unmet needs ratio, psychiatric comorbidities, other comorbidities

$p$-value less than 0.003 considered significant 


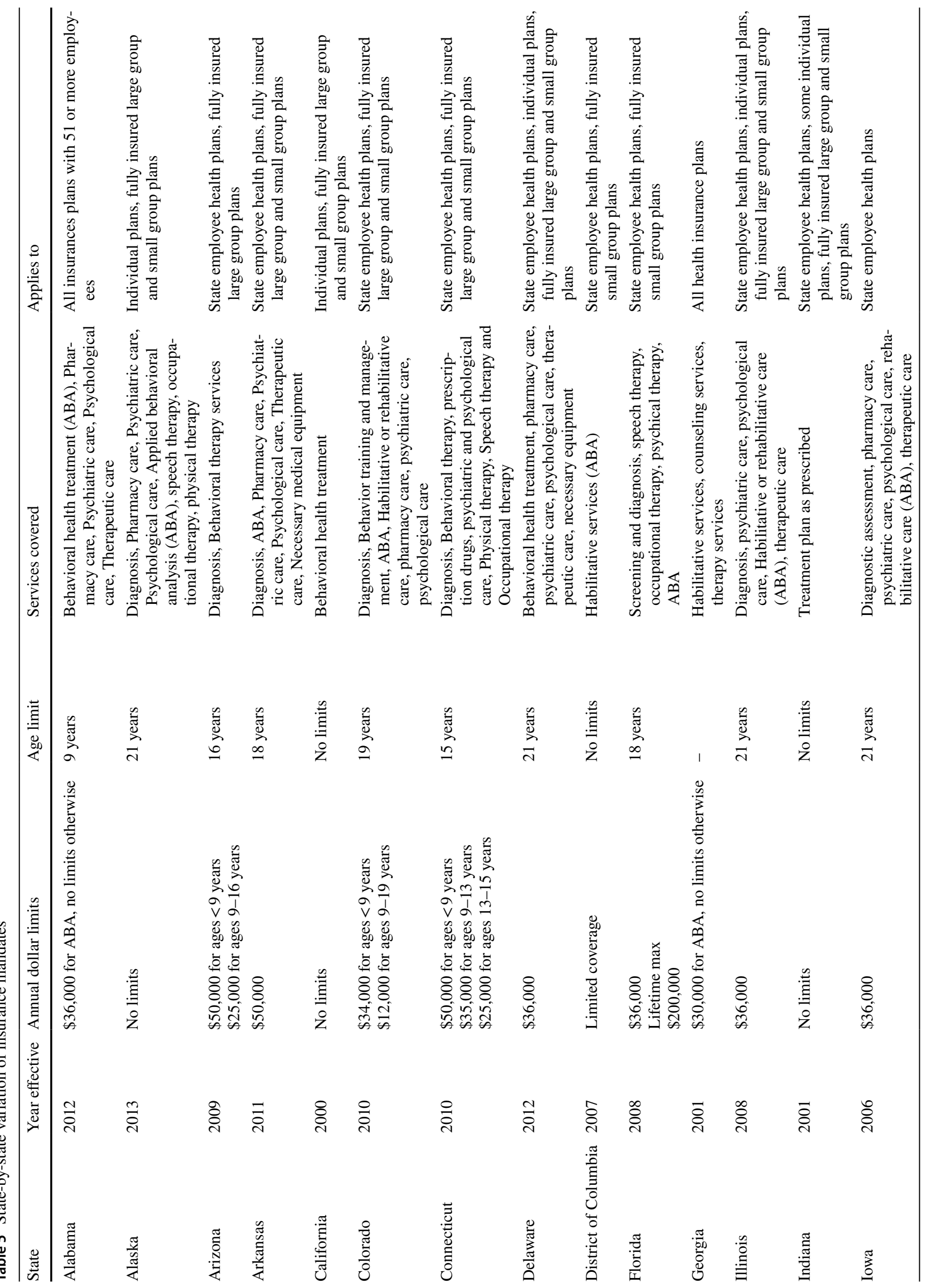




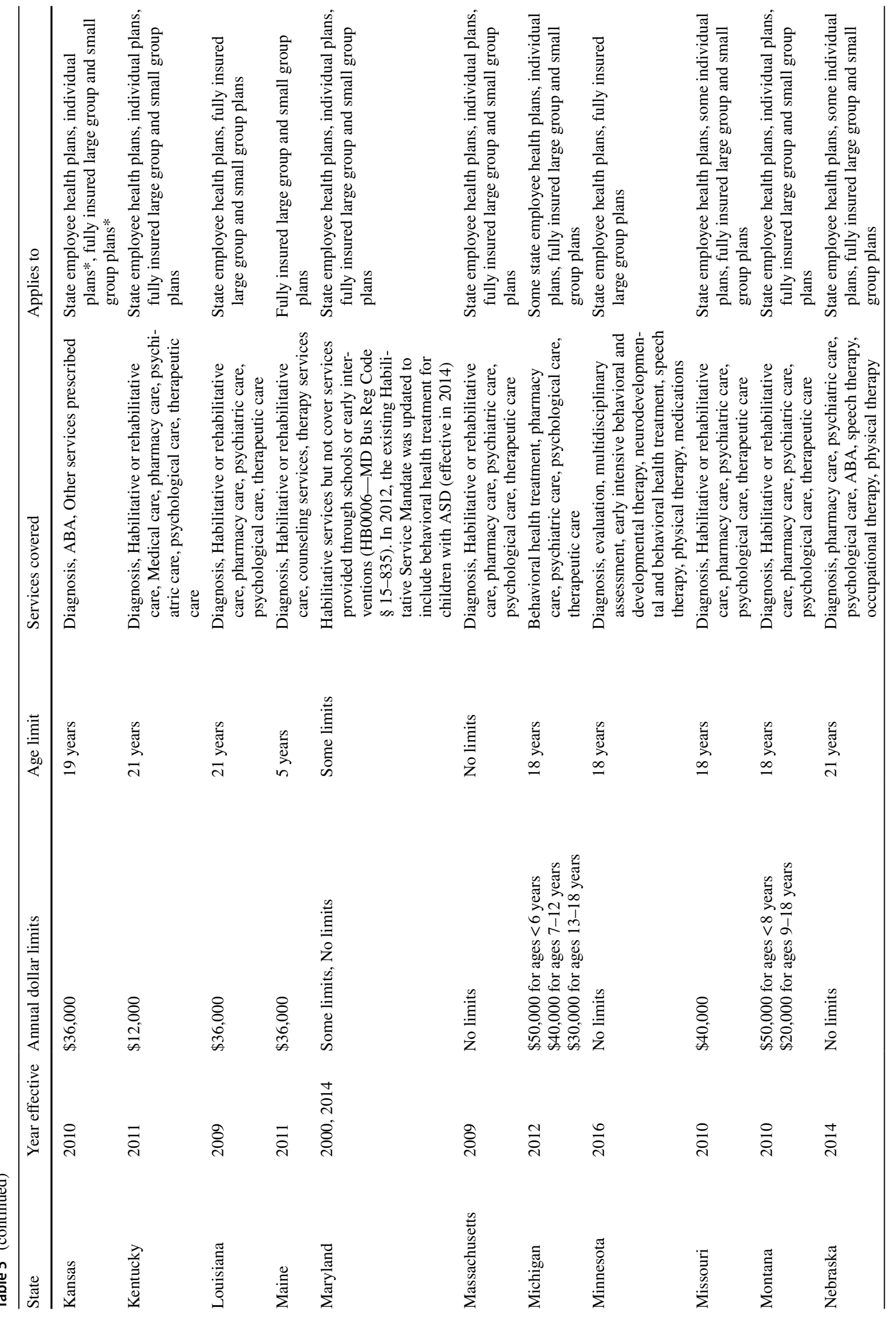




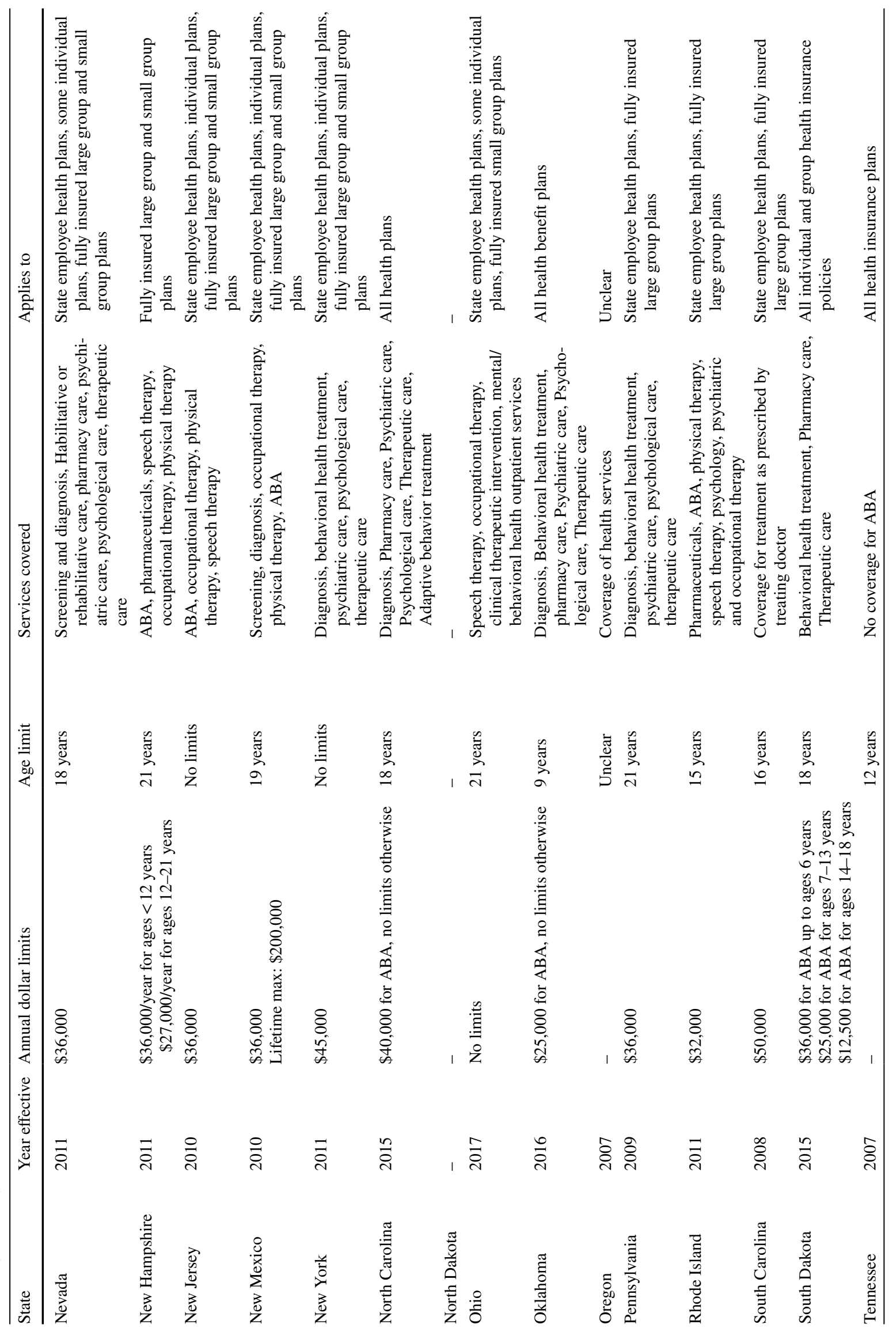




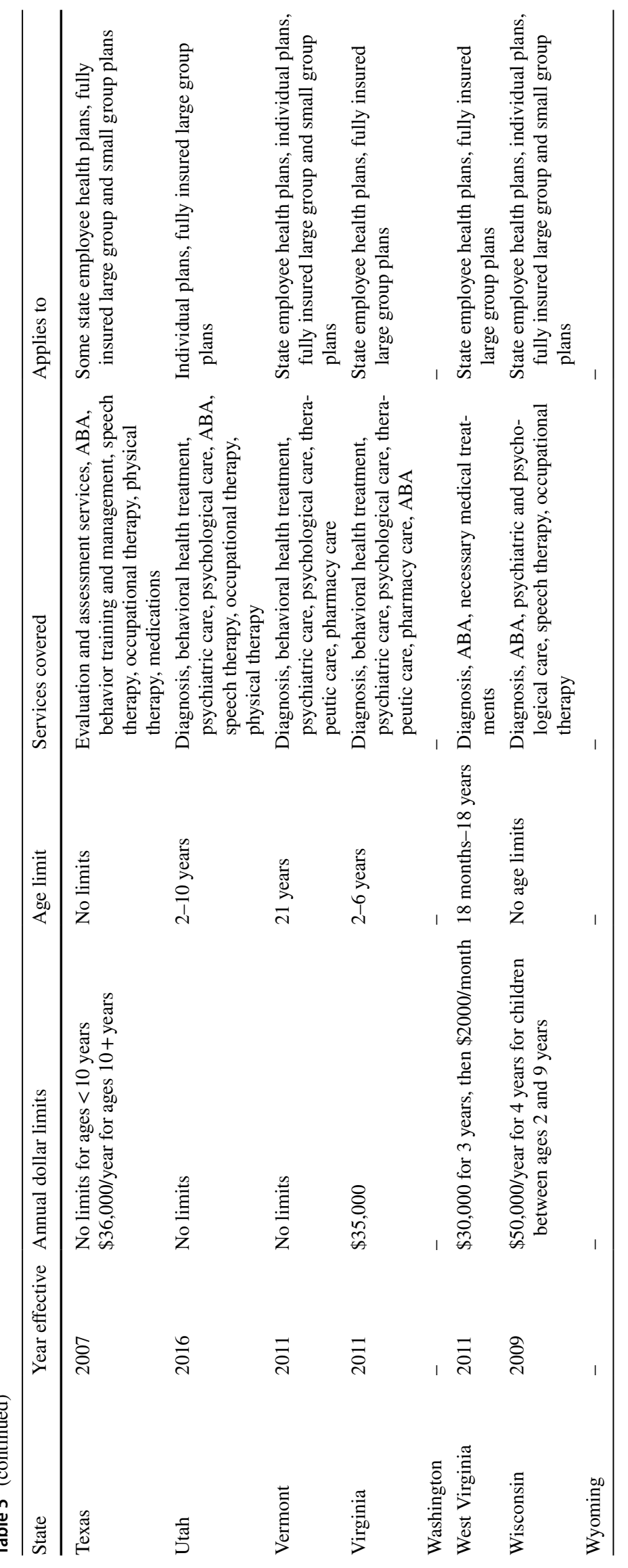

